\title{
LncRNA-1810034E14Rik reduces microglia activation in experimental ischemic stroke
}

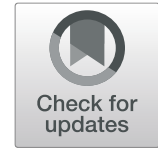

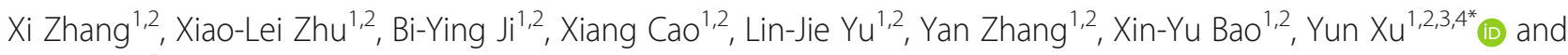 \\ Jia-Li Jin ${ }^{1,2^{*}}$
}

\begin{abstract}
Background: Activation of microglial cells plays an important role in neuroinflammation after ischemic stroke. Inhibiting the activation of microglial cells has been suggested as a potential therapeutic approach in the treatment of ischemic stroke.

Methods: Oxygen-glucose deprivation in primary microglial cells and transient middle cerebral artery occlusion (MCAO) in C57BL/6 mice were used as the in vitro and in vivo ischemic stroke models. Microarray analysis was performed to investigate the overall impact of long non-coding RNAs (IncRNAs) on the inflammation status of microglial cells. RT-qPCR was used to evaluate the IncRNA levels and mRNA levels of cytokines and microglial cell markers. ELISA was taken to measure the level of cytokines. Immunofluorescence was used to observe the activation of microglial cells. Western blotting was performed to test the p65 phosphorylation.

Results: In this study, we showed that LncRNA-1810034E14Rik was significantly decreased in LPS-treated or oxygenglucose deprivation-induced microglial cells. Overexpression of 1810034E14Rik decreased the infarct volume and alleviated brain damage in MCAO mice. 1810034E14Rik overexpression reduced the expression of inflammatory cytokines not only in ischemic stroke mice but also in oxygen-glucose deprivation-induced microglial cells. Moreover, 1810034E14Rik overexpression could suppress the activation of microglial cells and inhibit the phosphorylation of p65.
\end{abstract}

Conclusions: LncRNA-1810034E14Rik plays an anti-inflammatory role in ischemic stroke and regulates p65 phosphorylation, making it a potential target for stroke treatment.

Keywords: Ischemic stroke, IncRNA-1810034E14Rik, Microglial cells, p65

\section{Background}

Ischemic stroke is the second leading cause of death and disability in adults, resulting in a series of sequences, including cognitive impairment and epilepsy [1]. Although the pathophysiological mechanisms of stroke have been extensively studied, the only effective treatment for stroke is intravascular thrombolysis or thrombectomy $[1,2]$.

Inflammation after stroke is closely related to the progression and prognosis of stroke [3, 4]. However, there is still a lack of clinical approaches to effectively reverse inflammation induced by ischemia. Therefore, the discovery

\footnotetext{
* Correspondence: xuyun20042001@aliyun.com; 13585102165@126.com 1Department of Neurology, Drum Tower Hospital, Medical School and The State Key Laboratory of Pharmaceutical Biotechnology, Nanjing University, Nanjing 210008, China

Full list of author information is available at the end of the article
}

of new targets is particularly important for the development of ischemic stroke therapies.

Long non-coding RNA (LncRNA) is a set of transcripts that are longer than $200 \mathrm{bp}$, lacking or without an open reading frame (OFR), and that do not necessarily have polynucleotide tails [5-7]. The number of lncRNAs is much lower than that of coding protein genes (mRNAs). Compared with the coding protein gene, it has higher tissue/organ specificity. LncRNA is classified into antisense lncRNAs, intronic lncRNAs, divergent lncRNAs, intergenic lncRNAs, promoter upstream lncRNAs, promoter-associated lncRNAs and transcription start site-associated lncRNAs according to the relative position on the chromosome [8]. The functions of lncRNAs have not been fully clarified. Some studies have found that lncRNAs affect the transcription of the coding gene 
promoter and interfere with the expression of downstream genes $[9,10]$. Additionally, lncRNAs can interfere with the shearing of mRNA and form different shear forms [11]. There has been a great deal of research on lncRNAs in different diseases, but the function of lncRNAs in ischemic stroke is relatively unknown.

Microglial cells are resident immune cells in the central nervous system and act as a sensor in a normal brain [12]. Previous studies have found that microglial activation is associated with inflammation after stroke. Activated microglia secrete a large number of cytokines, such as IL-1b and TNF- $\alpha$, and attract peripheral neutrophils, macrophages and $\mathrm{T}$ cells to infiltrate around the infarcted cortex [12-14]. NF-kB plays a key role in regulating the immune response to infection. Incorrect regulation of NF- $\mathrm{KB}$ has been linked to cancer, inflammatory and autoimmune diseases, and improper immune development [15]. It has been well proven that the NF- $\kappa B$ signaling pathway is active during ischemic stroke. Previous studies found that suppressing the NF- $\mathrm{kB}$ signaling pathway protected against ischemic stroke by inhibiting excessive microglial activation and partly promoting neuronal survival [16]. Many researchers have observed an elevation of pro-inflammatory cytokine levels, enhanced nuclear NF- $\mathrm{kB}$ transcriptional activity, and increased nuclear translocation of NF- $\mathrm{kB}$ in experimental ischemia animals [15]. Interference with NF- $\mathrm{KB}$ signaling with p50 knockout mice reduced infarct size and helped functional recovery [17]. It has been reported that in Toll-like receptor 2-activated microglia, the subsequent NF- $\mathrm{kB}$ mediated production of TNF- $\alpha$, IL-10, and NO in a time-dependent manner [18]. These reports suggest that suppression of neuroinflammation and the NF- $\mathrm{KB}$ pathway may be a potential target for ischemic stroke.

In this study, we found that IncRNA-1810034E14Rik was reduced during OGD/MCAO injury in microglial cells. We observed that 1810034e14Rik protected against ischemic stroke in MCAO mice and overexpression of 1810034e14Rik in microglia could suppress the activation of microglial cells and the release of pro-inflammatory cytokines, which might be associated with inhibition of the NF-kB pathway. Thus, our study demonstrated that 1810034E14Rik played a vital role in cerebral ischemic damage, suggesting that 1810034E14Rik might be a potential target of stroke treatment.

\section{Methods}

\section{Animals}

Male, 7- to 8-week-old C57BL/6 mice (20-23 g in weight) were purchased from Model Animal Research Center of Nanjing University. The animals were raised in a regulated environment (12 h light/dark cycle) and were supplied with clean water and food. All the experiments involving animals were approved by the Institutional Animal Care and Use Committee of Nanjing University.

\section{Stereotaxic injection and focal ischemia}

Mice were anesthetized with $10 \%$ chloral hydrate $(3.2$ $\mathrm{ml} / \mathrm{kg}$ ) by intraperitoneal injection. A lentiviral vector $\left(1 \times 10^{9} \mathrm{TU} / \mathrm{ml}, \quad 1 \quad \mu \mathrm{l}\right)$ overexpressing IncRNA1810034E14Rik (Lv-1810034E14Rik) or negative control (Lv-control) was injected into the cerebral cortex with a stereotaxic instrument after the mice were anesthetized. Each mouse got three injections in the right cortex $(0.3$ $\mathrm{mm}$ front of the bregma, $0.8 \mathrm{~mm}$ behind the bregma, and $1.9 \mathrm{~mm}$ after the bregma; $3 \mathrm{~mm}$ lateral; and $1.8 \mathrm{~mm}$ deep). The injection was completed with a $10 \mu \mathrm{l}$ microsyringe at the rate of $0.1 \mu \mathrm{lmin}{ }^{-1}$.

Two weeks after injection, the mice were subjected to $\mathrm{MCAO}$ to induce focal ischemia as previously described [19]. Briefly, 8-week-old male C57BL/6 mice were anesthetized with $1.5 \%$ isoflurane in a $68.5 \% \mathrm{~N}_{2} \mathrm{O} / 30 \% \mathrm{O}_{2}$ mixture, the ischemia was induced by occlusion of the right MCA for $1 \mathrm{~h}$. Rectal temperature of each mouse was maintained at $37 \pm 0.5^{\circ} \mathrm{C}$ by a heating pad during the surgery.

Male C57BL/6J mice were randomly assigned to 4 groups $(N=15)$ : sham, MCAO $60 \mathrm{~min} / 24 \mathrm{~h}$ reperfusion, $\mathrm{MCAO} 60 \mathrm{~min} / 24 \mathrm{~h}$ reperfusion $+\mathrm{Lv}$-control (stereotactic injection of negative control lentivirus into cortex 2 weeks before MCAO), MCAO $60 \mathrm{~min} / 24 \mathrm{~h}$ reperfusion + Lv-LncRNA1810034E14Rik (stereotactic injection of lentivirus overexpressing 1810034E14Rik into cortex 2 weeks before MCAO).

\section{Neurological function evaluation}

The Rota-rod test, grip strength, and neurological symptom score (Additional file 1) were performed to assess neurological functions as previously described [20]. Investigators were blind to mouse group assignments.

\section{Cell culture and oxygen-glucose deprivation}

Primary microglial cells were prepared from postnatal 1-2 days C57BL/6 mice. After extracting the brain, the meninges were removed and the entire cortex in Leibovitz's L15 medium was isolated (Gibco Life Technologies). Then the nylon membrane (pore size of $70 \mathrm{mu}$ cell filter; Falcon, Pittsburgh, PA, USA) was used to dissociate the tissue mechanically. After centrifugation, the precipitates were suspended in Dulbecco's modified Eagle's medium, $10 \%$ fetal bovine serum (Myoclone; Gibco), and 1\% gentamicin (Gibco Life Technologies). Cells were grown in $5 \% \mathrm{CO} 2$ at $37^{\circ} \mathrm{C}$, and the medium was half-changed at day 5 . After culturing for 2 weeks, flasks were shaken gently and supernatant containing microglial cells was collected [21]. The obtained microglia cells were seeded into 24-well plates at a number of $5 \times 10^{5}$ per well for $6 \mathrm{~h}$ to adhere. 
The mature microglial cells were cultured with Dulbecco's modified Eagle's medium, 10\% fetal bovine serum (Myoclone; Gibco) and 1\% gentamicin (Gibco Life Technologies) and were treated with LPS $(100 \mathrm{ng} / \mathrm{ml}$, Escherichia coli 055: B5, Sigma, USA) for $3 \mathrm{~h}$ or $6 \mathrm{~h}$, and total RNA was extracted using a TRIzol commercial kit (Invitrogen, USA).

After transfection with Lv-1810034E14Rik for $48 \mathrm{~h}$, microglial cells were exposed to OGD for $4 \mathrm{~h}$ to imitate ischemia in vitro. Briefly, cultures were changed from the normal medium to the glucose-free medium. After flushing for $15 \mathrm{~min}$ with $5 \% \mathrm{CO} 2 / 95 \% \mathrm{~N} 2$ at $2 \mathrm{psi}(1 \mathrm{psi}=6.89$ $\mathrm{kPA})$, microglial cells were put in a hypoxia chamber (Billups-Rothenberg, Del Mar, CA). Then chambers were placed at $37^{\circ} \mathrm{C}$ for $4 \mathrm{~h}$. After OGD is ending, cells were returned to the normal medium and grown at normal conditions for $24 \mathrm{~h}$.

Primary cortical neurons were prepared from E16-17 mouse embryos. Cortices were dissected, treated with trypsin, and plated at $4 \times 10^{5} \mathrm{cell} / \mathrm{ml}$ on poly-D-lysine-coated 24-well plates or glass coverslips. Cells were grown in Neurobasal media supplemented with estrogen-free B27 supplement (Invitrogen, Carlsbad, CA, USA) and $25 \mathrm{nM}$ glutamine at $37^{\circ} \mathrm{C}$ in a humidified $5 \%$ $\mathrm{CO} 2$ incubator.

\section{RNA interference}

Small interfering RNA (siRNA) targeted at mouse 1810034E14Rik was used to silence 1810034E14Rik. A mixture of siRNA $(100 \mu \mathrm{mol} / \mathrm{L})$ and Lipofectamine RNAiMAX Transfection Reagent (Invitrogen, Carlsbad, CA, USA) was incubated at room temperature for $15 \mathrm{~min}$. The mix was added to microglial cells and incubated for $24 \mathrm{~h}$. The sequence of siRNA is 5'-GCCAGGAGAAACACTTTGA-3' (forward), 5'-GAGCAGTCCTTCGAATACT-3' (reverse). The sequence of nonsense control siRNA is $5^{\prime}$-UUC UCC GAA CGU GUC ACG UTT-3' (forward), 5'-ACG UGA CAC GUU CGG AGA ATT-3' (reverse).

\section{Cell viability assessment}

After being treated with microglia-free supernatants for $24 \mathrm{~h}, \mathrm{LDH}$ release assay (Beyotime Biotechnology, China) and cell counting kit-8 (CCK-8) analysis were used to measure the cell viability. In brief, $10 \mu \mathrm{l}$ of CCK-8 solution ( $5 \mathrm{mg} / \mathrm{ml}$; Sigma) was added to each well in incubated at $37^{\circ} \mathrm{C}$ for $2 \mathrm{~h}$. Then, the absorbance at $450 \mathrm{~nm}$ was measured with a microplate reader.

\section{Microarray analysis}

Total RNA of the cells was extracted by using a TRIzol commercial kit (Invitrogen, USA). And Quick Amp Labeling Kit, One-Color (Agilent, USA) was used to prepare labeling reaction. Then labeled/amplified RNA and labeled cRNA QC were purified by RNeasy Mini Kit
(Qiagen, German). After fragmentation, hybridization, and microarray wash, the microarray was scanned by Agilent Microarray Scanner (Agilent, USA). LncRNAs with differential expressions in primary microglial cells were picked out by the whole genome microarray expression profiling with the fold change $>2$ and adjusted $P<0.05$. The microarray analysis was performed with Agilent Feature Extraction by Oebiotech, Shanghai, China. In addition, sample preparation and microarray hybridization were performed according to the manufacturer's standard protocol with only minor modifications.

\section{Real-time polymerase chain reaction}

TRIzol commercial kit (Invitrogen, USA) was used to extract total RNA of the cells and tissues. The cDNA was synthesized using a reverse transcriptase kit (Takara, Japan). The primer sequences are listed in Additional file 2.

\section{Cytokine and chemokine measurements}

The levels of IL-1b, IL-6, TNF- $\alpha$, IL-4, and IL-10 in the supernatant of cell culture and cortical tissues were detected by the ELISA Kits (R\&D Systems, USA). The process was performed according to the instructions.

\section{Western blotting}

Protein from cortex was extracted and then quantified with Thermo Scientific BCA kit (USA). NE-PER Nuclear and Cytoplasmic Extraction Reagents was used for nucleo-cytoplasmic separation, and the operation was performed according to the protocol. In brief, $100 \mu \mathrm{l} \mathrm{Re}-$ agent $\mathrm{A}$ was added to the microglial cells. Twenty minutes later, centrifuging for $10 \mathrm{~min}$ at $3000 \times g$ and $4{ }^{\circ} \mathrm{C}$, collecting the supernatant. $150 \mu \mathrm{l}$ Reagent $\mathrm{B}$ was added to the sediment. Twenty minutes later, centrifuging for $10 \mathrm{~min}$ at $12000 \mathrm{~g}$ and $4{ }^{\circ} \mathrm{C}$, collecting the supernatant. Equal amounts of protein samples were separated by SDS-PAGE and blotted onto polyvinylidene fluoride (PVDF) membranes. The membranes were probed with primary antibodies against CD16 (ab 203,883, 1:1000), CD11b (ab13357, 1:1000), p-IKK (CST2697, 1:1000), p-p65(CST3033, 1:1000), p65(CST8242, 1:1000), ІкB (CST4812, 1:1000). GAPDH (CST5174, 1:5000) was used as a loading control. The secondary antibodies were goat anti-rabbit or anti-mouse IgG $(\mathrm{H}+\mathrm{L})$ HRP (Bioworld Technology, USA) and exposed to film.

\section{Immunofluorescence}

Cells/brain slices (20um) were fixed with $4 \%$ formalin, washed with PBS for three times, and then blocked by $2 \% \mathrm{BSA}$ for $2 \mathrm{~h}$ at room temperature. The samples were incubated with following primary antibodies at $4{ }^{\circ} \mathrm{C}$ overnight: antibodies for Iba1 (ab48004, 1: 200), NeuN (ab104224, 1:200), Cleaved-caspase3 (CST9664, 1:200), TMEM119 (ab209064, 1:200). Primary antibodies were 
detected by using goat anti-rabbit or anti-mouse secondary antibodies (1:200, Invitrogen, USA) for $1.5 \mathrm{~h}$ at room temperature. After washed with PBS for three times, the cells/brain slices were stained with $100 \mathrm{nM}$ DAPI (Sigma, USA) for $15 \mathrm{~min}$. Samples were observed and photographed (AX10, ZEISS, Germany).

\section{Statistical analysis}

Experimental results were shown as mean \pm SEM, and data were handled with SPSS 15.0 software. For those analyses with only one factor involved, the one-way ANOVA and multiple comparisons followed by Bonferroni tests were applied, while the two-way ANOVA and multiple comparisons followed by Tukey were used when two factors get involved. All statistical tests were two-sided with $P<0.05$ considered statistically significant.

\section{Results}

\section{Genome-wide IncRNA and mRNA expression during LPS} challenge in microglial cells

To determine the overall impact of lncRNAs on the inflammation status of microglial cells, a microarray was performed to analyze the expression of lncRNAs in LPS-induced microglial cells $(100 \mathrm{ng} / \mathrm{ml})$. The lncRNA expression profiles showed that 2453 IncRNAs (1337 upregulated/1116 downregulated) and 2367 lncRNAs (1352 upregulated/1015 downregulated) were significantly differentially expressed after 3 and $6 \mathrm{~h}$ of LPS stimulation (> 2 -fold change, $P<0.05$ ). Hierarchical clustering revealed systematic changes in IncRNA expression between control and LPS-induced samples (Fig. 1a, b). Then, we randomly selected seven IncRNAs (AW112010, AW011738, Mir22hg, U90926, Gpr137b-ps, F630028010Rik, and 1810034E14Rik), which showed a greater than 5-fold change, and the RT-qPCR results were consistent with the microarray analysis (Additional file 3). We performed GO and KEGG analysis for each lncRNA co-expressed mRNAs, and according to $P$ value, the frequency of each function prediction term was counted, and GO (or KEGG) term with more functional annotations was counted to reflect the overall situation of the functional distribution of IncRNAs. We selected the top 20 lncRNAs (or RNAs) to drawbar graph by frequency. The bioinformatics analysis showed that these statistically significant lncRNAs were correlated with several signaling pathways, including the TNF signaling pathway and Toll-like receptor signaling pathway (Additional file 3). Moreover, these IncRNAs were involved in the innate immune response, immune system process and apoptotic process (Additional file 3), which indicated that these IncRNAs were highly correlated with the inflammation state of microglial cells [15].

From the mRNA expression profiles, 1450 mRNAs (668 upregulated and 782 downregulated) were significantly differentially expressed between the control and the LPS-induced samples ( $\geq 2$-fold change, $P \leq 0.05) 3 \mathrm{~h}$ or $6 \mathrm{~h}$. Thirty-three mRNAs were upregulated nearly 100 -fold, and these mRNAs are mainly involved in the immune response. We observed that mRNAs involved in the NF- $\mathrm{KB}$ signaling pathway were extremely upregulated after LPS induction, which mean the NF- $\mathrm{kB}$ signaling pathway was activated.

\section{LncRNA-1810034E14Rik was significantly decreased in microglial cells after OGD}

To explore the role of specific lncRNAs involved in ischemia and hypoxia, we examined the mRNA levels of 7 lncRNAs (AW112010, AW011738, Mir22hg, U90926, Gpr137b-ps, F630028010Rik, and 1810034E14Rik) in microglial cells exposed to $4 \mathrm{~h}$ OGD with $3 \mathrm{~h}$ or $6 \mathrm{~h}$ reperfusion. The results showed that AW112010, AW011738, Mir22hg, and U90926 were significantly increased in $4 \mathrm{~h}$ OGD-treated microglial cells with $3 \mathrm{~h}$ and $6 \mathrm{~h}$ reperfusion (Fig. 1a-f), while Gpr137b-ps, F630028010Rik, and 1810034E14Rik were significantly reduced (Fig. 1g-i). Notably, lncRNA-1810034E14Rik was highly expressed in microglial cells and decreased significantly after OGD treatment. And we also tested the change of 1810034E14Rik in neurons, astrocytes, and endothelial cells after OGD induce, but no significant change was observed (Additional file 4).

\section{Upregulation of 1810034E14Rik affected the biological function of microglial cells}

It has been reported that the main biological functions of microglial cells include inflammation, migration, phagocytosis, and chemotaxis. To investigate the effects of lncRNA-1810034E14Rik on microglial functions, a lentivirus overexpressing lncRNA-1810034E14Rik or a negative control was used to infect primary microglial cells $(\mathrm{MOI}=20)$. As shown in Fig. $2 \mathrm{a}, \mathrm{h}$, the microglia change to a more activate morphology with a flattened cytoplasm in culture after $4 \mathrm{~h}$ of OGD/24 h of reperfusion. However, overexpression of lncRNA-1810034E14Rik reduced activated microglial cells, while knock-down of 1810034E14Rik increased activated microglial cells. And CCK-8 analysis showed that OGD had little effect on the viability of microglial cells (Fig. 2c). We also tested markers of pro-inflammatory microglial cells by RT-qPCR. OGD-induced upregulation of CD11b and CD16 was partially reversed by 1810034E14Rik overexpression and worsen by knock-down (Fig. 2d, e), which indicated that 1810034E14Rik reduced microglial activation induced by OGD. Subsequently, we detected the migration of microglial cells by scratch tests. The migration ability of microglia was increased after OGD, while 1810034E14Rik have no effect on the migration of microglia (Fig. 2f, i). To examine the phagocytic ability of microglial cells, $5 \mu \mathrm{m}$ red fluorescence microspheres were added 


\section{$\mathbf{a}$
$\substack{1.2 \\ 0.6 \\ 0.0 \\-0.6 \\-1.2}$
-1.6}
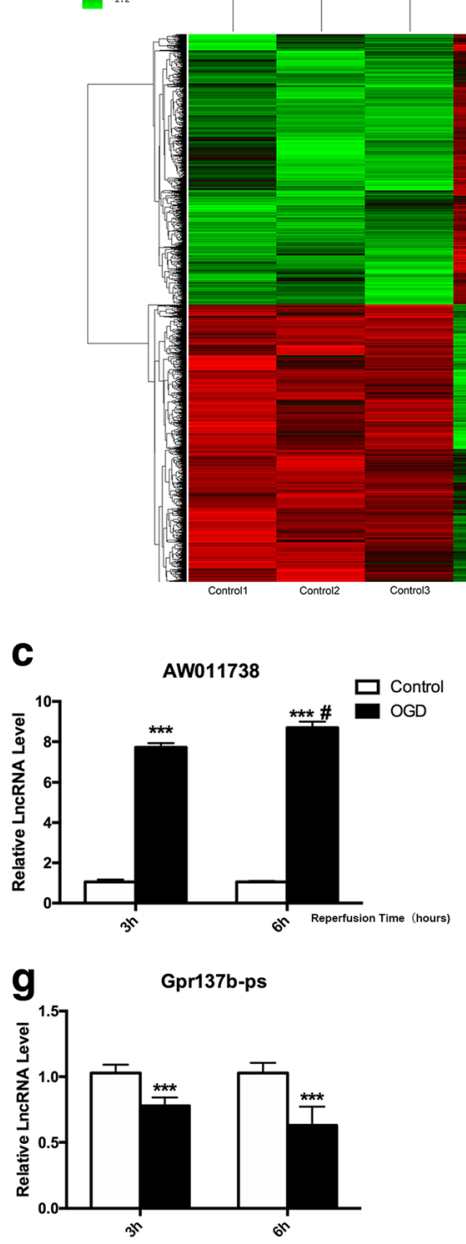

d
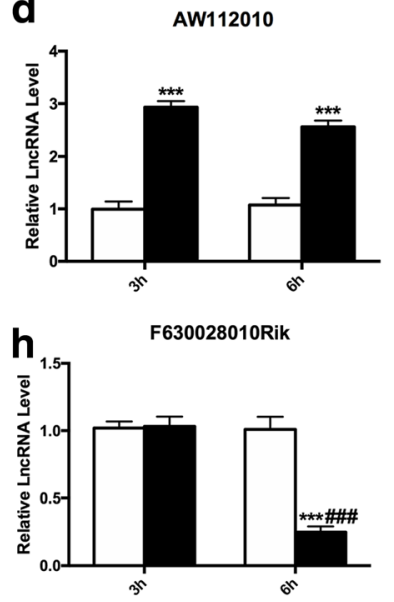

$\mathbf{b}$
0.2 .2
0.0
0.0 .0
-0.2

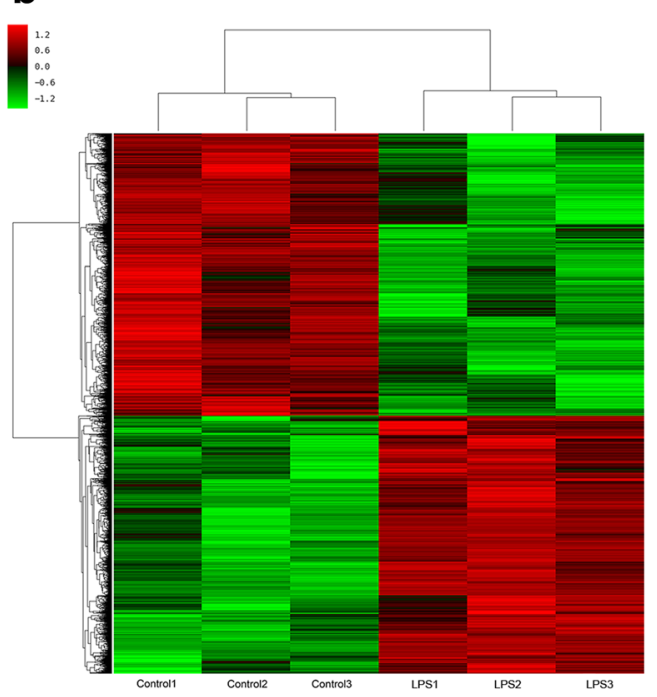

e

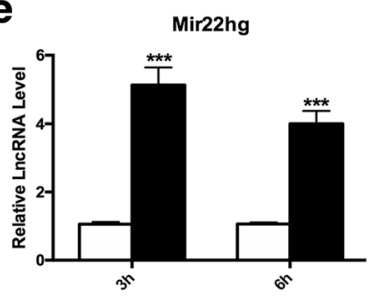

f
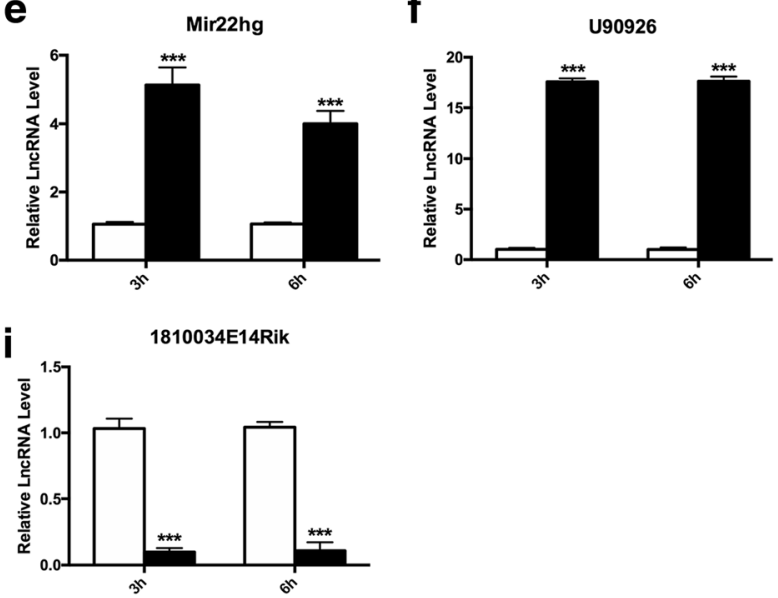

Fig. 1 LncRNA expression profile in LPS induced primary microglial cells. a, b Heat map of IncRNAs in microglial cells stimulated with LPS $(100 \mathrm{ng} / \mathrm{ml}$ ) for $3 \mathrm{~h}(\mathbf{a})$ or $6 \mathrm{~h}$ (b). c-i RT-qPCR validation of the expression of 7 IncRNAs (AW011738, AW112010, Mir22hg, U90926, Gpr137b-ps, F630028010Rik, and 1810034E14Rik) selected from differentially expressed IncRNAs in microglial cell underwent $4 \mathrm{~h}$ OGD/3 $\mathrm{h}$ reperfusion or $4 \mathrm{~h}$ OGD/6 $\mathrm{h}$ reperfusion. The data represents mean \pm SEM. $n=15,{ }^{* * *} P<0.001$ versus the control group; ${ }^{\#} P<0.05,{ }^{\# \# \#} P<0.001$ versus the $4 \mathrm{~h}$ OGD/3 $\mathrm{h}$ reperfusion group

to the culture of microglia after OGD $\left(10^{7} / \mathrm{ml}\right)$, and the phagocytosis of the microglia was observed after $3 \mathrm{~h}$ under a fluorescence microscope. The results showed that the number of microglia cells phagocytizing fluorescence microspheres increased after OGD, but 1810034E14Rik had no significant effect on the phagocytic function of microglial cells (Fig. 2g, j).

\section{Overexpression of 1810034E14Rik alleviated the inflammation status of microglial cells}

It is well known that inflammation induced by microglial cells is closely related to their activation. To observe the difference in microglial inflammation induced by OGD, we examined the changes in inflammatory factors in microglial cells by RT-qPCR. The inflammatory factors TNF- $\alpha$, IL- 6 , and IL-1b were significantly increased after $4 \mathrm{~h}$ of $\mathrm{OGD} / 24 \mathrm{~h}$ of reperfusion, and overexpression of lncRNA-1810034E14Rik reduced TNF- $\alpha$ and IL- $1 b$ but not IL- 6 . The levels of IL- 4 and IL-10 were elevated after OGD and significantly increased after overexpression of IncRNA-18100 34E14Rik, while knockdown of 1810034E14Rik aggravated inflammation status of microglial cells (Fig. 3b-f). Moreover, the inflammatory factors secreted by microglial cells in culture were detected by ELISA. Overexpression of IncRNA-1810034E14Rik significantly reduced TNF- $\alpha$ and IL-1b and increased IL-4 and IL-10 in OGD-induced microglial cells (Fig. $3 \mathrm{~g}-\mathrm{k}$ ), which was consistent with the results of RT-qPCR. Therefore, LncRNA-1810034E14Rik 

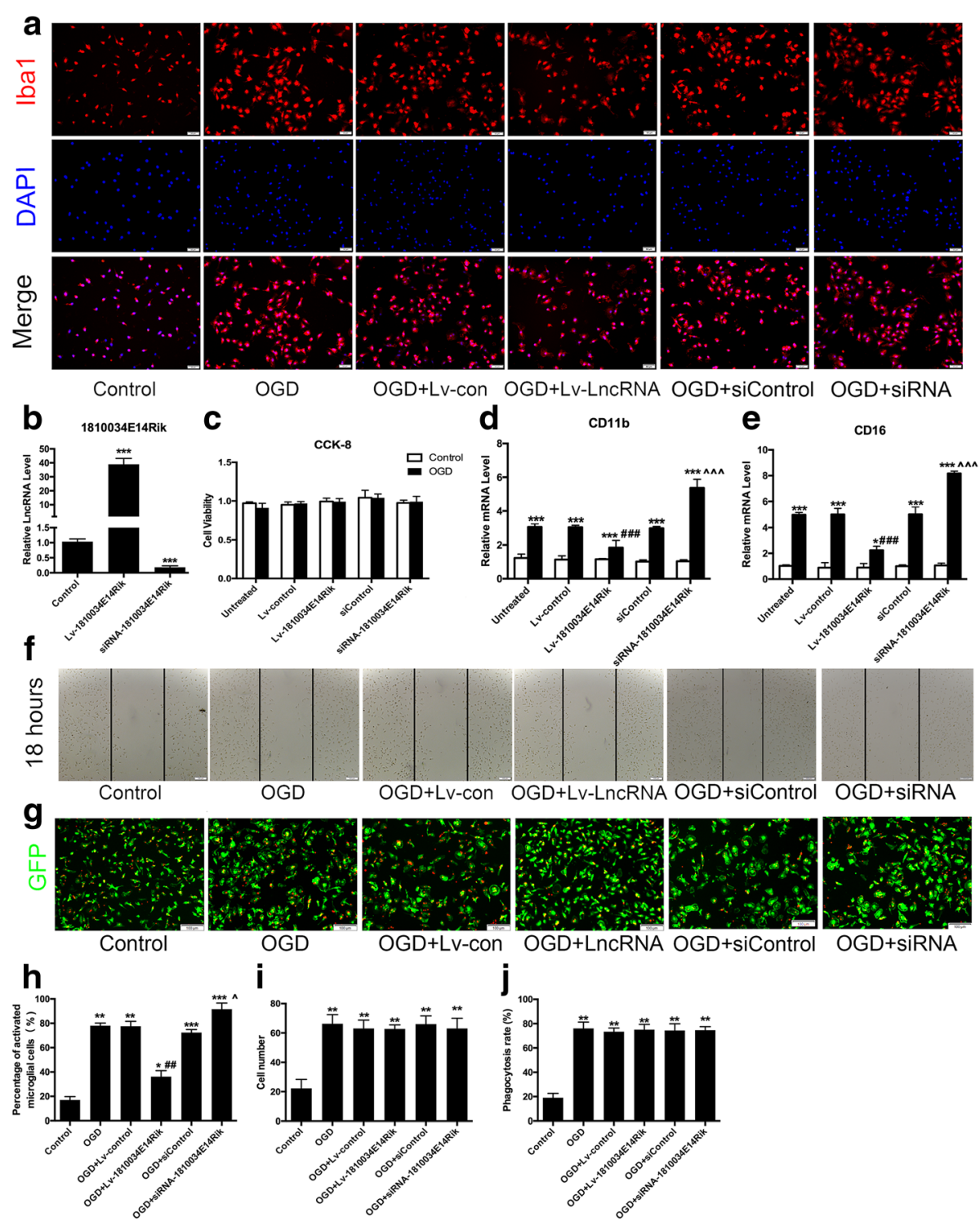

Fig. 2 Effects of 1810034E14Rik on the biological function of microglial cells. a Primary microglia were transfected with 1810034E14Rik or siRNA1810034 E14Rik for $24 \mathrm{~h}$ and then challenged with $4 \mathrm{~h} \mathrm{OGD/24} \mathrm{h}$ reperfusion to induce an ischemic state. Immunofluorescence staining of Iba1. b RT-qPCR validation of the expression of IncRNA-1810034E14Rik. c CCK-8 analysis of the viability of microglial cells. d, e RT-qPCR validation of the expression of CD11 b $\mathbf{d}$ and CD16 $\mathbf{e} . \mathbf{f}$ Cell migration of microglia was measured by scratch assay, and wound closure at $18 \mathrm{~h}$ was used to compare cell motility. $\mathbf{g} 5 \mathrm{\mu m}$ red fluorescent microspheres $\left(10^{6} / \mathrm{ml}\right)$ were added to culture to observe the phagocytosis of the microglia. $\mathbf{h}$ Quantification of Fig. 2a. i Quantification of Fig. 2f. j Quantification of Fig. 2g. The data represents mean \pm SEM. $n=15,{ }^{*} P<0.05,{ }^{*} P<0.01$, and ${ }^{* *} P<0.001$ versus the control

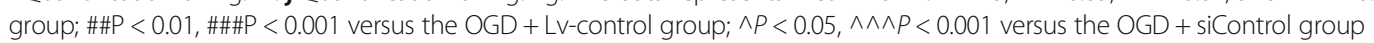

could suppress the inflammation status of microglial cells caused by OGD.

\section{E14Rik attenuated neuronal damage induced by microglial cells}

To elucidate the effects of microglial cells on neurons, we established neuronal microglial co-cultures. We used a conditioned medium transfer system without cell-cell contact. After transfection with a lentiviral vector that overexpressed lncRNA-1810034E14Rik for $24 \mathrm{~h}$ (MOI =
20), primary microglial cells underwent $4 \mathrm{~h}$ OGD $/ 24 \mathrm{~h}$ reperfusion. Then, microglia-free supernatants were collected and added to 5-day-old neurons. Neuronal survival was quantified $24 \mathrm{~h}$ later. LDH release assay and cell counting kit- 8 analysis showed that the death of neurons was increased and cell viability was decreased after treatment with supernatants of OGD-induced microglial cells. However, supernatants of OGD-induced microglial cells transfected with lncRNA-1810034E14Rik showed less cytotoxicity to neurons (Fig. 4a, b). Similar 

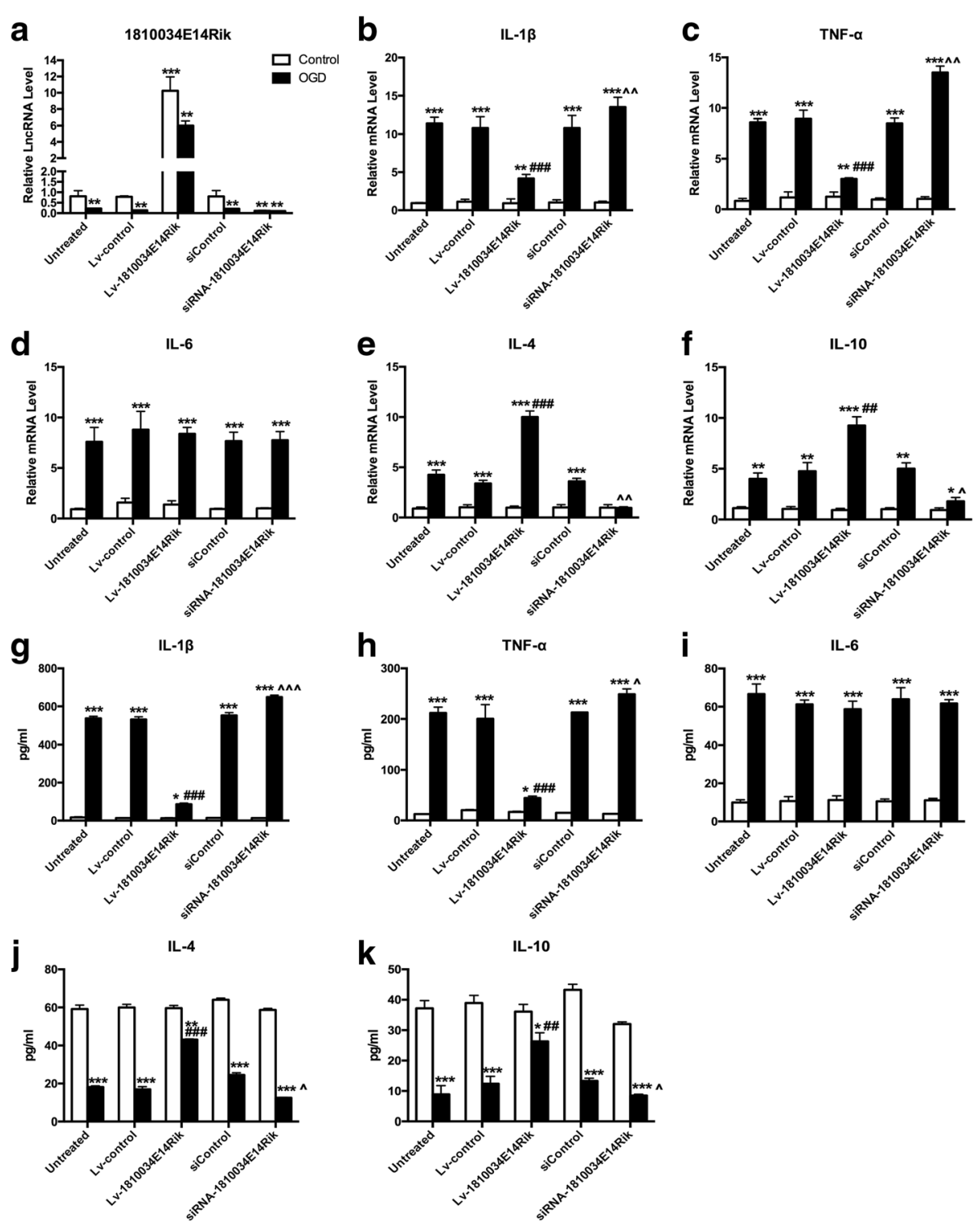

Fig. 3 Overexpression of 1810034E14Rik downregulated inflammatory factors in microglial cells. a The primary microglial cells were transferred with Lv-1810034E14Rik or negative control $24 \mathrm{~h}$ before OGD $4 \mathrm{~h} / \mathrm{R} 24 \mathrm{~h}$ induce. The expression of IncRNA-1810034E14Rik was detected by RT-qPCR. The mRNA levels of cytokines IL-1b (b), TNF-a c , IL-6 (d), IL-10 (e), and IL-4 (f) in primary microglial cells were determined by RT-qPCR. Cytokines such as TNF-a $(\mathbf{g}), I L-1 b(\mathbf{h}), I L-6(\mathbf{i}), I L-4(\mathbf{j})$, and IL10 (k) secreted by microglial cells were tested by ELISA. The data represents mean \pm SEM. $n=15,{ }^{*} P<0.05$, ${ }^{* *} P<0.01$, and ${ }^{* *} P<0.001$ versus the control group; ${ }^{\# \#} P<0.01,{ }^{\# \# \#} P<0.001$ versus the OGD group + Lv-control group; $\wedge P<0.05, \wedge \wedge P<0.01$, $\wedge \wedge \wedge P<0.001$ versus the $\mathrm{OGD}+$ siControl group

results also appeared in cleaved-caspase3 immunofluorescence. Cleaved-caspase3 was observed around the nucleus of neurons that were treated with supernatants of OGD-induced microglial cells. Additionally, there was less cleaved caspase- 3 around the nucleus of neurons in the OGD + IncRAN-1810034E14Rik group (Fig. 4c). Calcein-AM/PI Double staining also confirmed that overexpression of lncRNA-1810034E14Rik could mitigate neuron damage caused by OGD-induced microglial cells, and knockdown of 1810034E14Rik had the opposite effects (Fig. 4d).
1810034E14Rik ameliorated ischemic brain injury in vivo To investigate the role of lncRNA-1810034E14Rik in ischemic stroke in vivo, we first detected its level in the cortex of MCAO mice. As shown in Fig. 5a, lncRNA-1810034E14Rik was significantly downregulated in a time-dependent manner. And then we tested the change of other 5 lncRNAs(U90926, Gpr137b-ps, F630028010Rik, Mir22hg and AW0011738) in cortex of MCAO mice (Additional file 5). We observed that 1810034E14Rik had no effects on cerebral reperfusion after MCAO (Additional file 6). In addition, the relative level of 
a

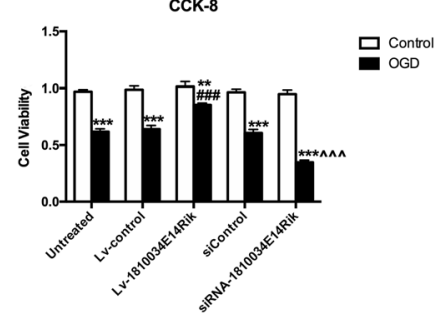

b

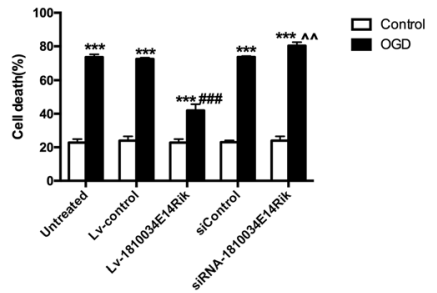

\section{C}

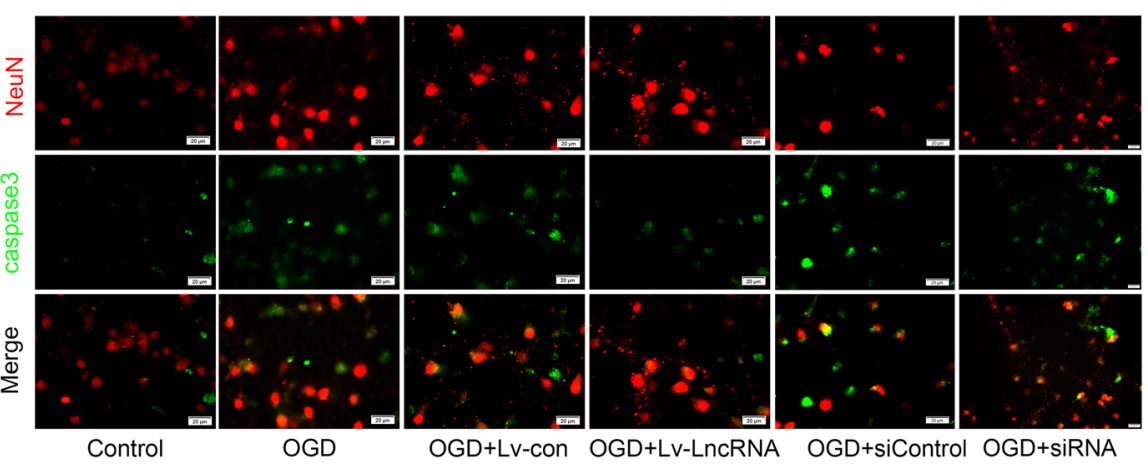

d

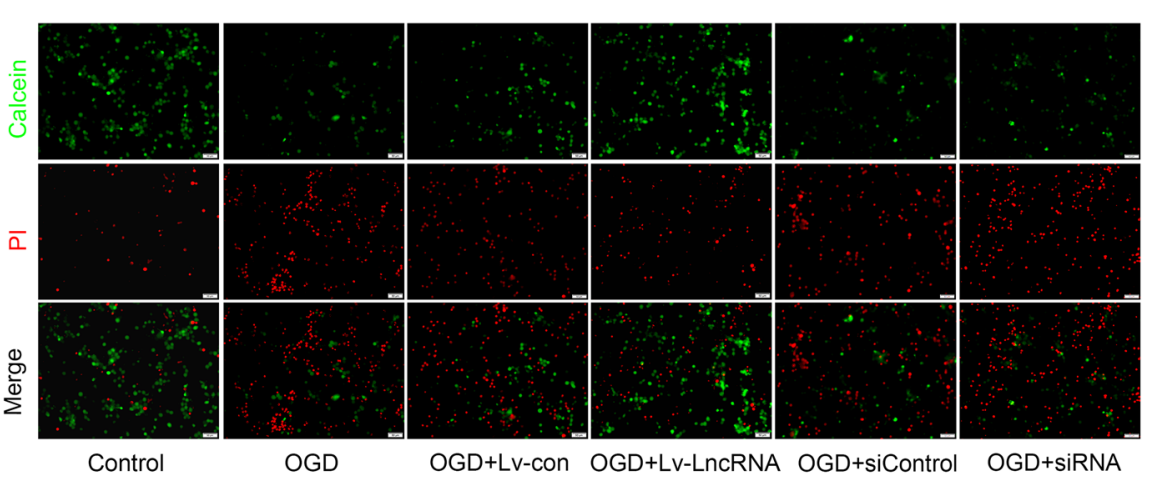

e

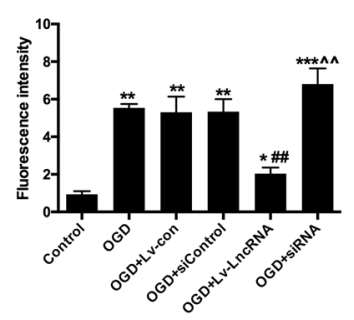

f

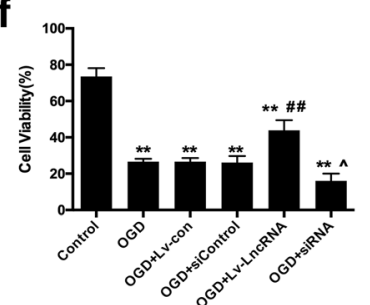

Fig. 4 1810034E14Rik ameliorated microglial cells induced neuron injury. a Supernatant culture of microglial cells with different treatment was collected and added to 5-day-old neurons at 1:4. Neuron death was measured by LDH released assay. $\mathbf{b}$ Cell counting Kit-8 assay of neurons treated with the culture of microglial cells. c Representative double-staining immunofluorescence of NeuN and cleaved-caspase3 in neurons. $\mathbf{d}$ Calcein-AM/PI co-staining immunofluorescence of Neurons. The data represents mean \pm SEM. $n=15, * P<0.05,{ }^{* *} p<0.01$, and ${ }^{* * *} P<0.001$ versus the control group;

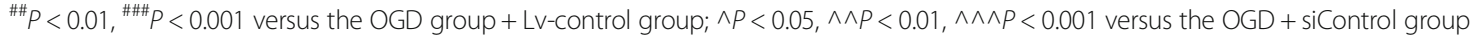

lncRNA-1810034E14Rik was significantly increased after Lv-1810034E14Rik injection (Fig. 5b, c). Then, we tested the motor function of mice after MCAO. The results showed that the exercise performance of mice was seriously impaired, but the MCAO+Lv-lnc1810034E14Rik group showed less motor function damage compared to the $\mathrm{MCAO}+\mathrm{Lv}$-control group (Fig. 5d-f described separately). In addition, IncRNA-1810034E14Rik alleviated the water content of the infarcted cortex after MCAO (Fig. 5g). After reperfusion, 1810034E14Rik-overexpressing mice had smaller infarcts by TTC staining (Fig. 5h, i). These results suggest that overexpression of 1810034E14Rik attenuated ischemic brain damage.

Overexpression of 1810034E14Rik decreased pro-inflammatory cytokine levels in vivo

It has been widely accepted that inflammation contributes to ischemic brain injury. We therefore detected 

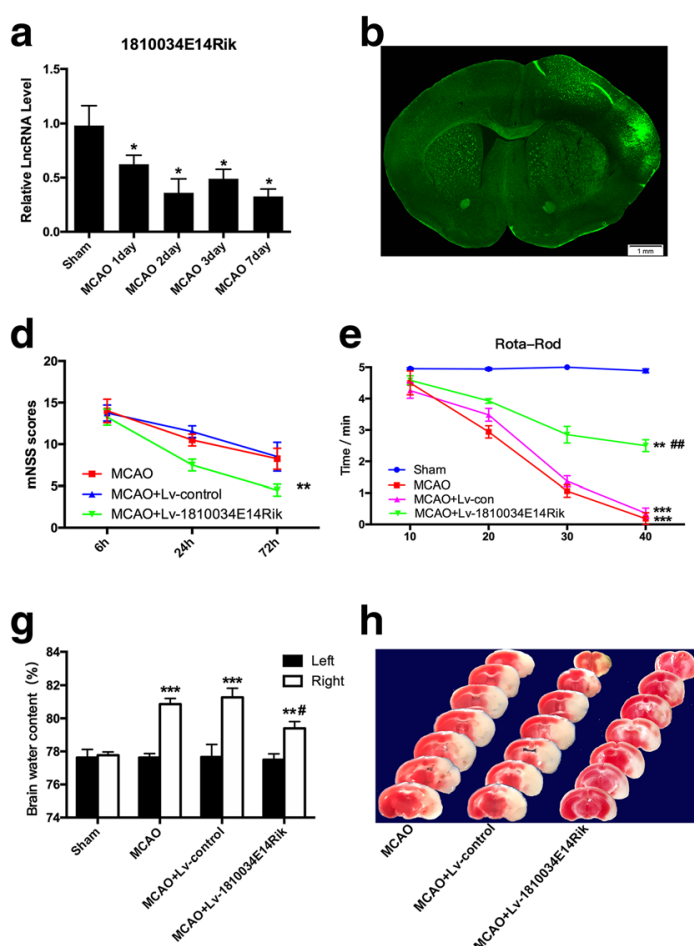

h

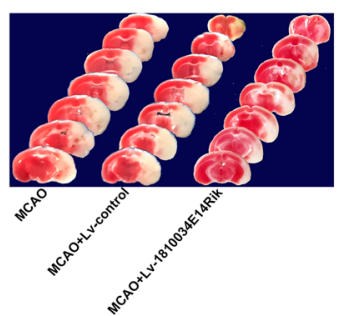

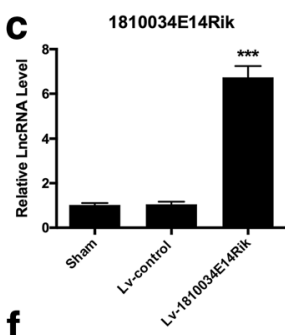

f
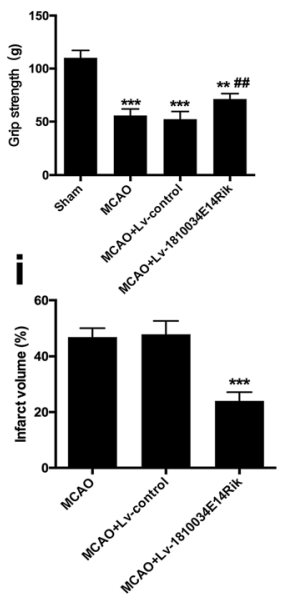

Fig. 5 1810034E14Rik improved brain damage after $1 \mathrm{~h}$ MCAO/24 h reperfusion. a The expression of IncRNA-1810034E14Rik in the infarcted cortex at day 1, day 2, day 3, and day 7 was tested by RT-qPCR. b A 1810034E14Rik lentiviral vector expressing GFP was infected in the mice cortex by a stereotactic instrument. c The expression of 1810034E14Rik was examined by RT-qPCR in the cortex after injection. The neurological severity scores $(\mathbf{d})$, rota-rod test (e), and grip strength $(\mathbf{f})$ were performed to evaluate functional outcome after MCAO. $\mathbf{g}$ Brain water content was examined to measure brain edema severity. $\mathbf{h}$, i Infarct volume after MCAO was confirmed by TTC staining. The data represents mean \pm SEM. $n=15,{ }^{*} P<0.05,{ }^{* *} P<0.01$, and ${ }^{* * *} P<0.001$ versus the sham group; ${ }^{\#} P<0.05$ and ${ }^{\# \#} P<0.01$ versus the MCAO group

whether altered expression of 1810034E14Rik could regulate the inflammatory response. Using RT-qPCR, we measured the mRNA levels of three pro-inflammatory cytokines, IL-1b (Fig. 6a), TNF- $\alpha$ (Fig. 6b), and IL-6 (Fig. 6c), and two anti-inflammatory cytokines, IL-10 (Fig. 6d) and IL-4 (Fig. 6e), in the infarcted cortex of mice. MCAO significantly increased the mRNA production of all three pro-inflammatory factors. Overexpression of 1810034E14Rik reduced MCAO-induced IL-1b and TNF- $\alpha$ levels and enhanced IL-10 and IL-4 levels. The results of the ELISA assay supported the mRNA change in the infarcted cortex (Fig. $6 f-j$ ). These data suggested that 1810034E14Rik has anti-inflammatory roles in the ischemic stroke model.

\section{Overexpression of 1810034E14Rik reduced the activation of microglial cells in vivo}

It has been reported that activation of microglial cells is closely related to ischemic brain injury. As shown in Fig. 7a, microglial cells were activated in the ischemic penumbra, and 1810034E14Rik significantly decreased the activation of microglia. Meanwhile, the mRNA and protein levels of two markers of activated microglial cells, CD16 and CD11b, were significantly decreased in MCAO-treated mice after overexpression of 1810034E14Rik (Fig. 7b-d). These results indicated that 1810034E14Rik overexpression ameliorated the activation of microglial cells and the inflammatory response after MCAO treatment.

1810034E14Rik reduced activation of microglia probably by inhibiting the NF-KB pathway

The NF- $\mathrm{kB}$ pathway is a classic inflammatory signaling pathway. Our previous research found that the NF-kB pathway in microglial cells was activated after OGD. The MCAO and OGD treatment reduced the level of $I_{k} \mathrm{~B}$ and the hyperphosphorylation of p65 (Fig. 8a, b). However, overexpression of $1810034 \mathrm{E} 14 \mathrm{Rik}$ could suppress the over-activation of the NF-kB pathway. The results of nucleocytoplasmic separation showed that 1810034E14Rik reduced the transfer of p65 to the nucleus after OGD in microglial cells (Fig. 8c). Thus, we conjectured that 1810034E14Rik played an anti-inflammatory role probably by regulating the NF- $\mathrm{kB}$ pathway.

\section{Discussion}

It has been widely reported that IncRNAs play an important role in physiological and pathological responses in several diseases, but their function in cerebral 


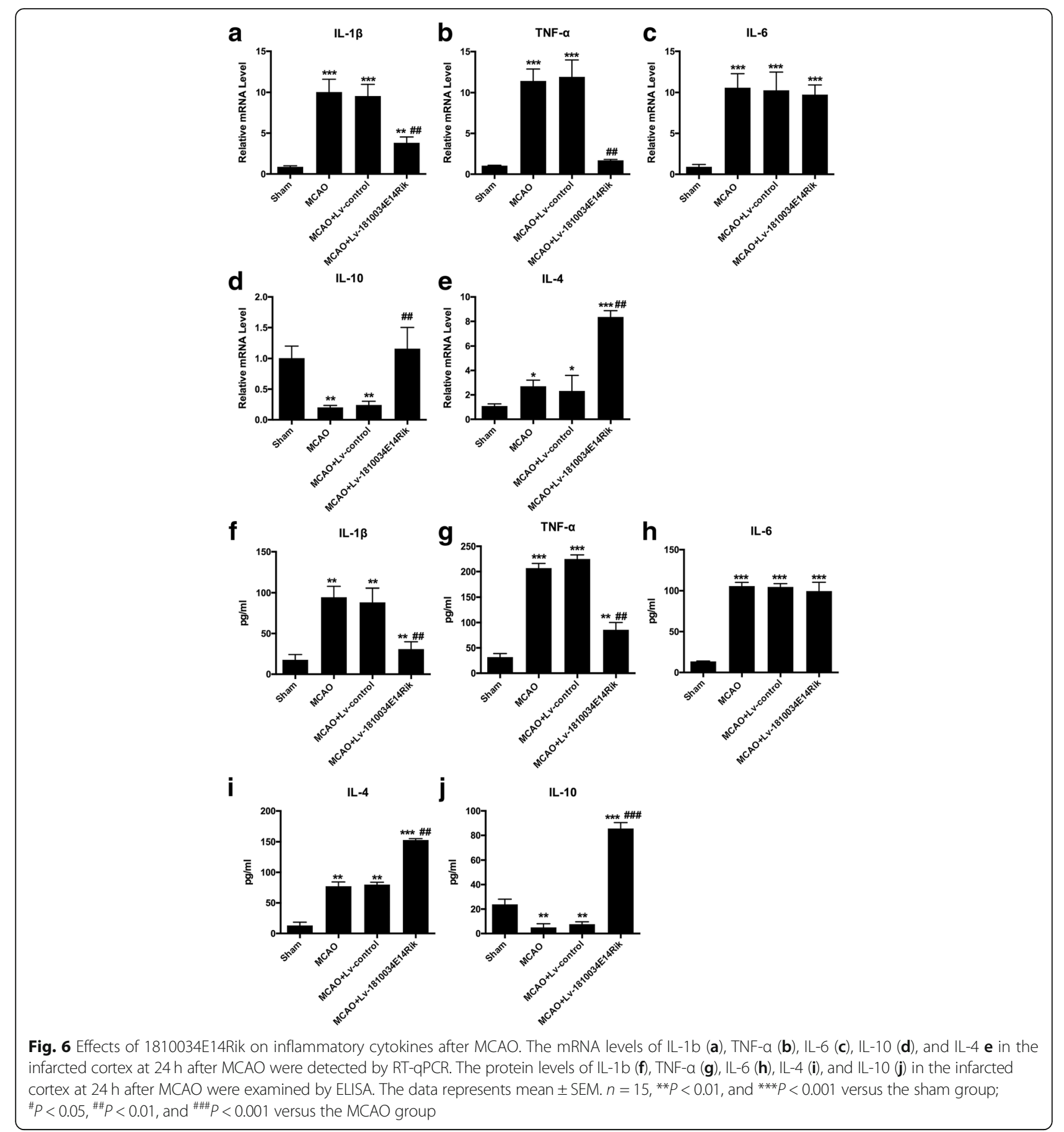

ischemia remains unknown [22, 23]. In this study, we found that 1810034E14Rik, a lncRNA associated with inflammatory responses, is downregulated both in OGDand LPS-induced microglial cells. Using an MCAO mouse model, we found that overexpression of 1810034E14Rik significantly improved behaviors and decreased infarct volume and brain edema in the acute stage. In the infarcted cortex, the pro-inflammatory factors TNF- $\alpha$ and IL-1b were negatively influenced, while the anti-inflammatory factors IL-10 and IL-4 were significantly increased after 1810034E14Rik overexpression. In addition, we determined that the overexpression of 1810034E14Rik could reduce the activation of microglial cells in the infarcted cortex. Taken together, these data suggest a potential role for 1810034E14Rik in regulating the inflammatory response after stroke. Notably, upregulation of 1810034E14Rik suppressed the activation of microglial cells induced by OGD in vitro and affected 
a

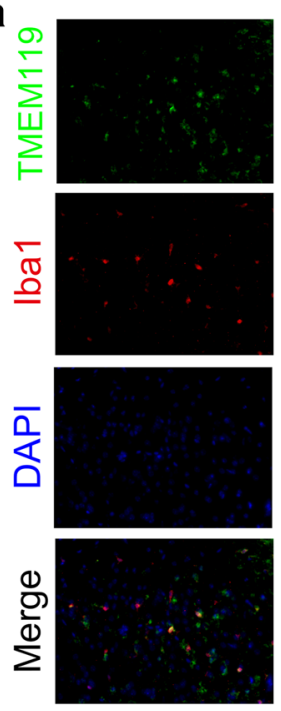

Sham
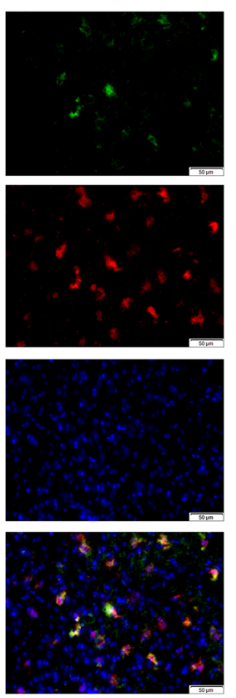

MCAO
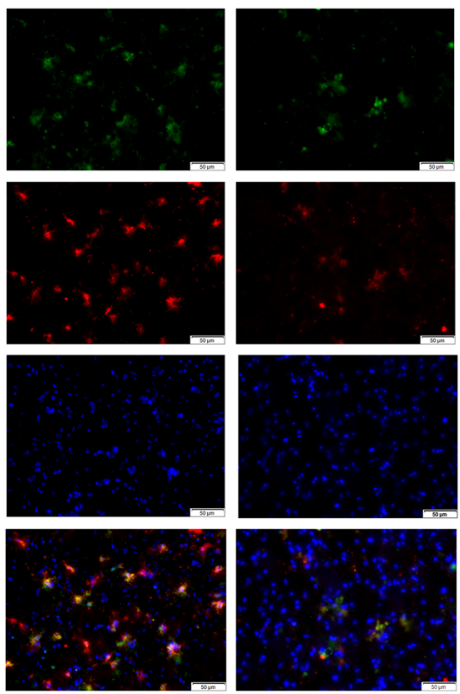

MCAO+LV-CON
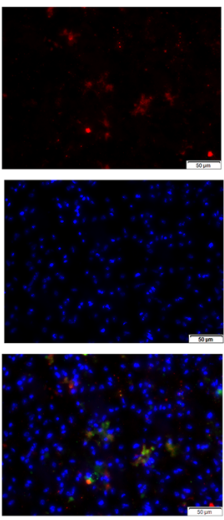

MCAO+Lv-LnCRNA

b

CD11b

C

CD16
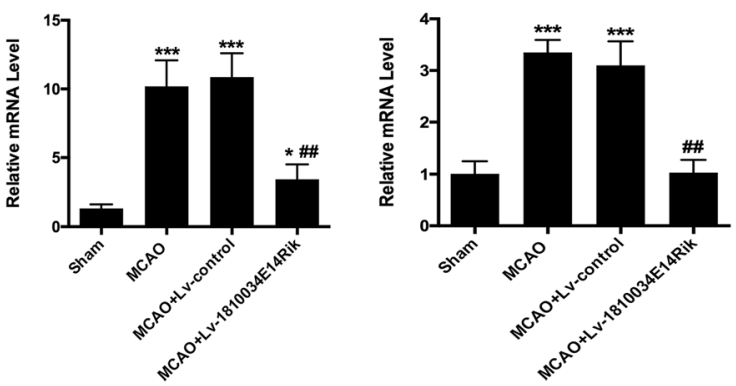

d

Sham MCAO MCAO+LV-Con MCAO+Lv-LnCRNA

CD16

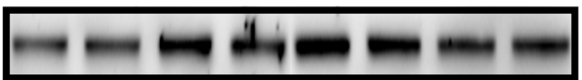

CD11b

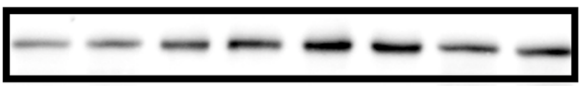

GAPDH

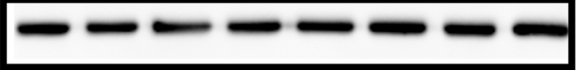

Fig. 7 1810034E14Rik overexpression reversed MCAO induced microglia activation. a Representative staining immunofluorescence of Iba1+ and TMEM119+ cells. RT-qPCR for CD11b $\mathbf{b}$ and CD16 $\mathbf{c}$ in the infarcted cortex. $\mathbf{d}$ Western blotting of CD11b and CD16 expression in whole ipsilateral cortex tissue. The data represents mean \pm SEM. $n=15,{ }^{*} P<0.05$ and ${ }^{* * *} P<0.001$ versus the sham group; ${ }^{* \#} P<0.01$ versus the MCAO group

their biological function, including reduced inflammation. Overall, our studies support that 1810034E14Rik has an improvement in ischemic stroke, and its anti-inflammatory effects are achieved by affecting microglial activation.

Microglial cells, a member of the mononuclear phagocytic cell family, are distributed throughout the central system and are the smallest glial cells, accounting for approximately $5-10 \%$ of the total glial cells [24]. As immune effector cells resident in the central nervous system, microglial cells and their mediated neuro-inflammation play a very important role in the damage of the central nervous system and the process of disease progression [25]. Microglial cells have been widely recognized as the primary immune effector in the central nervous system and are involved in many neurological diseases, including ischemic stroke, HIV encephalopathy, Parkinson's disease, and Alzheimer's disease [26]. Microglial cells can be activated under pathological conditions, even under very weak stimuli, which manifest as local proliferation and aggregation to different degrees, often accompanied by cell morphology, immunophenotype, and functional changes [27]. Numerous studies have investigated the role of microglial cells in ischemic stroke. Wan S et al. found that polarized microglia occurred dynamically after ischemic stroke, and PAR-1 participated in the activation and polarization of microglial cells [28]. Liesz A et al. reported 

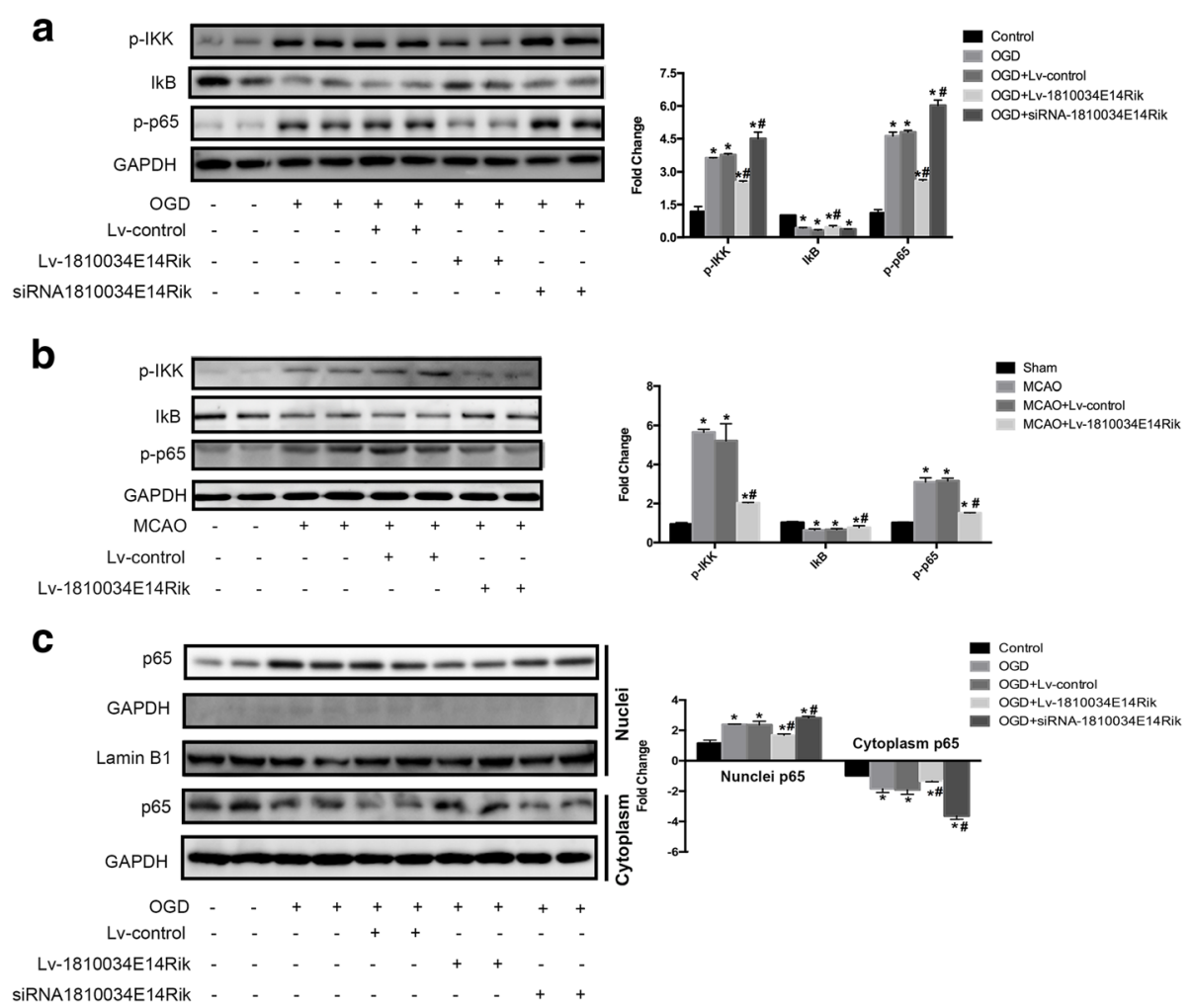

Fig. 8 Overexpression of 1810034E14Rik could suppress the activation of NF-KB signaling pathway. a Protein levels of $p$-IKK, IKB, and p-p65 in primary microglial cells were tested by western blotting. $\mathbf{b}$ Protein levels of $\mathrm{p}-\mathrm{IKK}$, IKB, and p-p65 in the infarcted cortex of MCAO mice were examined by western blotting. $\mathbf{c}$ Protein levels of p65 in nuclei and cytoplasm of primary microglial cells were measured by western blotting separately. The data represents mean \pm SEM. $n=15,{ }^{*} P<0.05$ versus the sham group or control group; ${ }^{*} P<0.05$ versus the MCAO group or OGD group

that the absence of Treg cells augmented the post-ischemic activation of resident and invading inflammatory cells, including microglia and $\mathrm{T}$ cells, the main sources of deleterious cerebral tumor necrosis factor-alpha (TNF- $\alpha)$ and interferon-gamma (IFN-gamma), respectively [29]. Li T et al. discovered that CX3CR1 $(\mathrm{GFP} /+)$ infiltrating cells and reactive microglia represented two distinct populations of cells with different functions and therapeutic potentials for the treatment of stroke [30]. Ma Y et al. summarized the effects of microglia activation on neuronal apoptosis, neurogenesis, and brain function recovery after cerebral ischemia. Differential polarization of microglia may help explain the biphasic effect of microglia on ischemia [31]. In our study, microglial cells were activated in the infarcted cortex after MCAO and secreted IL1, TNF- $\alpha$, and IL6. However, overexpression of 1810034E1 4Rik reversed the increase in cytokines, which was consistent with the results in primary microglial cells challenged with OGD.

Inflammation plays a key role in all stages of ischemic stroke. A variety of inflammatory cells and cytokines are involved in this process, a role for lncRNAs in stroke is now being investigated. However, there are many studies on lncRNAs related to their function during stroke. Mehta SL et al. identified that lncRNA-FosDT could modulate post-stroke behavioral deficits and brain damage by its interactions with Sin3a and coREST and subsequent depression of GRIA2, NF-kB, and GRIN1 [32]. Q Xu et al. discovered that lncRNA C2dat1 modulated the expression of CaMKII $\delta$ to impact neuronal survival through the $\mathrm{NF}-\mathrm{kB}$ signaling pathway and might be a potential target for therapeutic intervention of ischemic brain injury [33]. $\mathrm{XJ}$ Zhang et al. found that lncRNA Malat1 could regulate cerebrovascular pathologies in ischemic stroke [34]. Jue Wang et al. reported that $\mathrm{H} 19$ promoted neuroinflammation by driving HDAC1-dependent M1 microglial polarization [35]. Wen Y et al. found that lncRNA Gm4419 contributes to OGD/R injury of cerebral microglial cells via IкB phosphorylation and NF- $\kappa B$ activation [36].

1810034E14Rik, a long non-coding RNA, was screened by lncRNA microarray analysis. It was significantly decreased both in OGD-induced microglial cells and in the infarcted cortex. To date, there are no studies on the function of lncRNA-1810034E14Rik in any disease. Bioinformatics suggested that it might be involved in the innate immune response and apoptotic process. Additionally, we validated that 1810034E14Rik could attenuate the inflammatory response caused by activated 
microglial cells. In recent years, although the research of lncRNAs has achieved preliminary results, especially in tumor and neurodegenerative diseases, no lncRNA therapy or biomarker has been applied to clinical patients [37]. However, lncRNAs have been used a treatment in animals in tumor researches. It has been reported that antisense oligonucleotides targeting IncRNA-MALAT1 could reduce tumor growth and metastasis [38]. But lncRNA used as a treatment in ischemic stroke has not been reported.

Emerging studies have shown that NF-kB signaling is a pivotal driver of the inflammatory response because it can transcriptionally activate downstream pro-inflammatory cytokines such as IL-1b, TNF- $\alpha$, and IL-6 [39]. A previous study provided that the NF- $\mathrm{kB}$ signaling pathway was over-activated in microglial cells after stroke [15]. The results of mice with p50 KO suggested that NF-kB activation aggravated ischemic neuronal damage, but its effects differed in different cells. Activation of NF- $\mathrm{kB}$ in microglial cells promoted ischemic neuronal death, but in neurons, activated NF- $\mathrm{kB}$ may increase their survival after ischemia [40]. In our research, we focused on the activation of NF- $\kappa B$ in microglial cells. We observed a decrease in p-IкB and an increase in p-p65 in microglial cells after OGD, and the transfer of p65 in the nucleus was also induced. In addition, overexpression of 1810034E14Rik could reverse the above changes caused by ischemia.

\section{Conclusion}

In summary, lncRNA-1810034E14Rik contributes to brain protection from cerebral ischemic insults and to the inhibition of neuroinflammation. Furthermore, the anti-inflammatory role of 1810034E14Rik after ischemia in vivo or in vitro is highly correlated with its function in the suppression of the NF- $\mathrm{kB}$ pathway in microglial cells. Our results suggest that lncRNA-1810034E14Rik may become a potential treatment for the inflammatory response after ischemic stroke.

\section{Additional files}

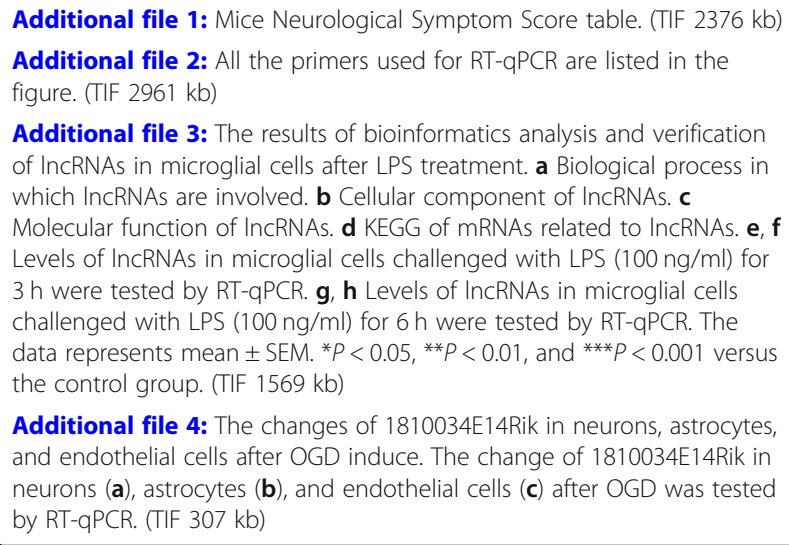

Additional file 3: The results of bioinformatics analysis and verification of IncRNAs in microglial cells after LPS treatment. a Biological process in which IncRNAs are involved. b Cellular component of IncRNAs. c Molecular function of IncRNAs. $\mathbf{d}$ KEGG of mRNAs related to IncRNAs. e, $\mathbf{f}$ Levels of IncRNAs in microglial cells challenged with LPS (100 ng/ml) for $3 \mathrm{~h}$ were tested by RT-qPCR. $\mathbf{g}$, $\mathbf{h}$ Levels of IncRNAs in microglial cells challenged with LPS $(100 \mathrm{ng} / \mathrm{ml})$ for $6 \mathrm{~h}$ were tested by RT-qPCR. The data represents mean \pm SEM. ${ }^{*} P<0.05$, ${ }^{* *} P<0.01$, and ${ }^{* * *} P<0.001$ versus the control group. (TIF $1569 \mathrm{~kb}$ )

Additional file 4: The changes of 1810034E14Rik in neurons, astrocytes, and endothelial cells after OGD induce. The change of 1810034E14Rik in neurons (a), astrocytes (b), and endothelial cells (c) after OGD was tested by RT-qPCR. (TIF $307 \mathrm{~kb}$ )

Additional file 5: Verification of IncRNAs in the infarcted cortex of MCAO mice. Levels of IncRNA-U90926 (a), Gpr137b-ps (b), F630028010Rik (c), Mir22hg (d), and AW0011738 (e) were tested by RT-qPCR. The data represents mean \pm SEM. ${ }^{*} P<0.05$, ${ }^{* *} P<0.01$, and ${ }^{* *} P<0.001$ versus the sham group. (TIF $678 \mathrm{~kb}$ )

Additional file 6: 1810034E14Rik had no effects on cerebral perfusion. A cerebral perfusion of mice during MCAO was measured by laser speckle imaging. (TIF $9361 \mathrm{~kb}$ )

\section{Abbreviations}

BSA: Bovine serum albumin; LncRNA: Long non-coding RNA;

LPS: Lipopolysaccharide; MCAO: Middle cerebral artery occlusion;

OGD: Oxygen and glucose deprivation; ORF: Open reading frame; RT-

qPCR: Real-time quantitative PCR; TTC: Triphenyl tetrazolium chloride

\section{Acknowledgements}

The authors thank Oebiotech for its contribution to microarray analysis, Yan Chen and Yue Chen for critical suggestions in statistical analysis.

\section{Funding}

This research was supported by the National Natural Science Foundation of China (81630028, 81671055, 81300988), the National Key Research and Development Program of China (2016YFC1300504), the Natural Science Foundation (BE2016610, BK20160123) of Jiangsu Province of China, Jiangsu Province Key Medical Discipline (ZDXKA2016020), Jiangsu Province Medical Youth Talent (QNRC2016024), and Nanjing Medical Science and Technique Development Foundation (QRX17119).

\section{Availability of data and materials}

All data generated or analyzed during this study are included in this published article and its supplementary information files.

\section{Authors' contributions}

$J \sqcup J$ and $Y X$ designed the experiments. $J J$ and $X Z$ performed the experiment and drafted the manuscript. XLZ and BYJ analyzed the data. XC contributed to the experimental design. LJY performed the intro-cortex LV-1810034E14Rik injection. YZ established the MCAO mice model. XYB contributed to cell culture. All authors have read and approved the final manuscript.

\section{Ethics approval and consent to participate}

All the experiments involving animals were approved by the Institutional Animal Care and Use Committee of Nanjing University. This study was approved by the ethics committee at Nanjing Drum Tower Hospital, Nanjing University Medical School.

\section{Consent for publication}

Not applicable.

\section{Competing interests}

The authors declare that they have no competing interests.

\section{Publisher's note}

Springer Nature remains neutral with regard to jurisdictional claims in published maps and institutional affiliations.

\section{Author details}

${ }^{1}$ Department of Neurology, Drum Tower Hospital, Medical School and The State Key Laboratory of Pharmaceutical Biotechnology, Nanjing University, Nanjing 210008, China. ${ }^{2}$ Jiangsu Key Laboratory for Molecular Medicine, Medical School of Nanjing University, Nanjing 210008, China. ${ }^{3}$ Jiangsu Province Stroke Center for Diagnosis and Therapy, Nanjing 210008, China. ${ }^{4}$ Nanjing Neuropsychiatry Clinic Medical Center, Nanjing 210008, China.

Received: 17 October 2018 Accepted: 26 March 2019 Published online: 08 April 2019

\section{References}

1. Fisher M, Saver JL. Future directions of acute ischaemic stroke therapy. Lancet Neurol. 2015;14(7):758-67. 
2. Anderson CS, Robinson T, Lindley Rl, Arima H, Lavados PM, Lee TH, et al Low-dose versus standard-dose intravenous Alteplase in acute ischemic stroke. N Engl J Med. 2016;374(24):2313-23.

3. Hankey GJ. Stroke. Lancet. 2017;389(10069):641-54

4. ladecola C, Anrather J. The immunology of stroke: from mechanisms to translation. Nat Med. 2011:17(7):796-808.

5. Carpenter S. Long noncoding RNA: novel links between gene expression and innate immunity. Virus Res. 2016;212:137-45.

6. Zhang X, Hamblin MH, Yin KJ. The long noncoding RNA Malat1: its physiological and pathophysiological functions. RNA Biol. 2017;14(12):1705-14.

7. Chen LL. Linking long noncoding RNA localization and function. Trends Biochem Sci. 2016:41(9):761-72.

8. Batista PJ, Chang HY. Long noncoding RNAs: cellular address codes in development and disease. Cell. 2013;152(6):1298-307.

9. Turner M, Galloway A, Vigorito E. Noncoding RNA and its associated proteins as regulatory elements of the immune system. Nat Immunol. 2014; 15(6):484-91.

10. Meller VH, Joshi SS, Deshpande N. Modulation of chromatin by noncoding RNA. Annu Rev Genet. 2015:49:673-95.

11. Rutenberg-Schoenberg M, Sexton AN, Simon MD. The properties of long noncoding RNAs that regulate chromatin. Annu Rev Genomics Hum Genet. 2016;17:69-94.

12. Wang $\mathrm{S}$, Zhang $\mathrm{H}, \mathrm{Xu} \mathrm{Y}$. Crosstalk between microglia and T cells contributes to brain damage and recovery after ischemic stroke. Neurol Res. 2016;38(6): 495-503.

13. Pan J, Jin $J$, Ge HM, Yin KL, Chen X, Han $\amalg$, et al. Malibatol A regulates microglia M1/M2 polarization in experimental stroke in a PPARgammadependent manner. J Neuroinflammation. 2015;12:51.

14. Meng H-L, Li X-X, Chen Y-T, Yu L-J, Zhang H, Lao J-M, et al. Neuronal soluble Fas ligand drives M1-microglia polarization after cerebral ischemia. CNS Neurosci Ther. 2016;22(9):771-81.

15. Venna VR, Weston G, Benashski SE, Tarabishy S, Liu F, Li J, et al. NF-kappaB contributes to the detrimental effects of social isolation after experimental stroke. Acta Neuropathol. 2012;124(3):425-38.

16. Su L, Zhang R, Chen Y, Zhu Z, Ma C. Raf kinase inhibitor protein attenuates ischemic-induced microglia cell apoptosis and activation through NFkappaB pathway. Cell Physiol Biochem. 2017;41(3):1125-34.

17. Cui L, Duchamp NS, Boston DJ, Ren X, Zhang X, Hu H, et al. NF-kappaB is involved in brain repair by stem cell factor and granulocyte-colony stimulating factor in chronic stroke. Exp Neurol. 2015;263:17-27.

18. Han L, Yin K, Zhang S, Wu Z, Wang C, Zhang Q, et al. Dalesconols B inhibits lipopolysaccharide induced inflammation and suppresses NF-kappaB and p38/JNK activation in microglial cells. Neurochem Int. 2013;62(7):913-21.

19. Han L, Cai W, Mao L, Liu J, Li P, Leak RK, et al. Rosiglitazone promotes white matter integrity and long-term functional recovery after focal cerebral ischemia. Stroke. 2015;46(9):2628-36.

20. Yang W, Chen X, Pan J, Ge H, Yin K, Wu Z, et al. Malibatol a protects against brain injury through reversing mitochondrial dysfunction in experimental stroke. Neurochem Int. 2015:80:33-40.

21. Li J, Zhang S, Lu M, Chen Z, Chen C, Han L, et al. Hydroxysafflor yellow a suppresses inflammatory responses of BV2 microglia after oxygen-glucose deprivation. Neurosci Lett. 2013;535:51-6.

22. Abraham JM, Meltzer SJ. Long noncoding RNAs in the pathogenesis of Barrett's esophagus and esophageal carcinoma. Gastroenterology. 2017;153:27-34.

23. Beermann J, Piccoli MT, Viereck J, Thum T. Non-coding RNAs in development and disease: background, mechanisms, and therapeutic approaches. Physiol Rev. 2016;96:1297-325.

24. Yin Y, Qiu S, Li X, Huang B, Xu Y, Peng Y. EZH2 suppression in glioblastoma shifts microglia toward $M 1$ phenotype in tumor microenvironment. J Neuroinflammation. 2017;14(1):220

25. Chen S, Dong Z, Cheng M, Zhao Y, Wang M, Sai N, et al. Homocysteine exaggerates microglia activation and neuroinflammation through microglia localized STAT3 overactivation following ischemic stroke. J Neuroinflammation. 2017;14(1):187.

26. Salter MW, Beggs S. Sublime microglia: expanding roles for the guardians of the CNS. Cell. 2014;158:15-24.

27. Nayak D, Roth TL, McGavern DB. Microglia development and function. Annu Rev Immunol. 2014;32:367-402.

28. Wan S, Cheng Y, Jin H, Guo D, Hua Y, Keep RF, et al. Microglia activation and polarization after intracerebral hemorrhage in mice: the role of protease-activated Receptor-1. Transl Stroke Res. 2016;7(6):478-87.
29. Liesz A, Suri-Payer E, Veltkamp C, Doerr H, Sommer C, Rivest S, et al. Regulatory $T$ cells are key cerebroprotective immunomodulators in acute experimental stroke. Nat Med. 2009;15(2):192-9.

30. Li T, Pang S, Yu Y, Wu X, Guo J, Zhang S. Proliferation of parenchymal microglia is the main source of microgliosis after ischaemic stroke. Brain. 2013;136(Pt 12:3578-88.

31. Ma Y, Wang J, Wang Y, Yang GY. The biphasic function of microglia in ischemic stroke. Prog Neurobiol. 2017;157:247-72.

32. Mehta SL, Kim T, Vemuganti R. Long noncoding RNA FosDT promotes ischemic brain injury by interacting with REST-associated chromatinmodifying proteins. J Neurosci. 2015;35(50):16443-9.

33. Xu Q, Deng F, Xing Z, Wu Z, Cen B, Xu S, et al. Long non-coding RNA C2dat1 regulates CaMKIldelta expression to promote neuronal survival through the NF-kappaB signaling pathway following cerebral ischemia. Cell Death Dis. 2016:7:e2173.

34. Zhang X, Tang X, Liu K, Hamblin MH, Yin KJ. Long noncoding RNA Malat1 regulates cerebrovascular pathologies in ischemic stroke. J Neurosci. 2017; 37(7):1797-806

35. Wang J, Zhao H, Fan Z, Li G, Ma Q, Tao Z, et al. Long noncoding RNA H19 promotes neuroinflammation in ischemic stroke by driving histone deacetylase 1-dependent M1 microglial polarization. Stroke. 2017:48(8):2211-21.

36. Wen Y, Yu Y, Fu X. LncRNA Gm4419 contributes to OGD/R injury of cerebral microglial cells via IkappaB phosphorylation and NF-kappaB activation. Biochem Biophys Res Commun. 2017:487(4):923-9.

37. Ulitsky I. Evolution to the rescue: using comparative genomics to understand long non-coding RNAs. Nat Rev Genet. 2016;17:601-14.

38. Matsui M, Corey DR. Non-coding RNAs as drug targets. Nat Rev Drug Discov. 2017;16:167-79.

39. Zhang F, Yan C, Wei C, Yao Y, Ma X, Gong Z, et al. Vinpocetine inhibits NFkappaB-dependent inflammation in acute ischemic stroke patients. Transl Stroke Res. 2018;9(2):174-84.

40. Yang $\mathrm{CH}$, Yen TL, Hsu CY, Thomas PA, Sheu JR, Jayakumar T. Multi-targeting Andrographolide, a novel NF-kappaB inhibitor, as a potential therapeutic agent for stroke. Int J Mol Sci. 2017;18(8):1638.

Ready to submit your research? Choose BMC and benefit from

- fast, convenient online submission

- thorough peer review by experienced researchers in your field

- rapid publication on acceptance

- support for research data, including large and complex data types

- gold Open Access which fosters wider collaboration and increased citations

- maximum visibility for your research: over $100 \mathrm{M}$ website views per year

At $\mathrm{BMC}$, research is always in progress.

Learn more biomedcentral.com/submissions 